\title{
A study of cutaneous adverse drug reactions in the outpatient department of Dermatology at a tertiary care center in Gujarat, India
}

\author{
Dinesh A. Chavda ${ }^{1 *}$, Satish D. Suthar ${ }^{2}$, Shradhanand Singh ${ }^{3}$, Jayesh D. Balat ${ }^{2}$, \\ Sailesh P. Parmar ${ }^{2}$, Suresh D. Mistry ${ }^{4}$
}

\begin{abstract}
${ }^{1}$ Department of Pharmacology, G.M.E.R.S. Medical College, Junagadh, Gujarat, India ${ }^{2}$ Department of Pharmacology, Shri M. P. Shah Govt. Medical College, Jamnagar, Gujarat, India

${ }^{3}$ Department of Medical Affair, Novartis Healthcare Pvt. Ltd. Mumbai, India

${ }^{4}$ Department of Pharmacology, GMERS, Valsad, Gujarat, India
\end{abstract}

Received: 12 February 2017

Revised: 20 March 2017

Accepted: 28 March 2017

*Correspondence to:

Dr. Dinesh A. Chavda,

Email:

drdineshchavda@yahoo.com

Copyright: (C) the author(s), publisher and licensee Medip Academy. This is an openaccess article distributed under the terms of the Creative Commons Attribution NonCommercial License, which permits unrestricted noncommercial use, distribution, and reproduction in any medium, provided the original work is properly cited.

\begin{abstract}
Background: The data for adverse cutaneous drug reactions (ACDRs) is limited in Gujarat. The ACDRs are one of the frequent ADRs and cause of significant morbidity and mortality in patients of all areas of healthcare today. They are responsible for significant number of hospital admissions. Thus, the present study emphasises on the need and importance of an effective pharmacovigilance programme.

Methods: A prospective study was undertaken in a 183 cases tertiary care teaching hospital of India. Male to female ratio, most common class of drug, individual drug causing ACDR, common types of ACDRs Parameters were studied. Other Parameters like Causality, preventability and severe or nonsevere reactions were analyzed.

Results: Majority of the patients (48\%) with CADR belonged to the age group 25-44 followed by 45-64 (28\%). Most frequent adverse cutaneous drug reactions reported were Urticaria (40\%), Maculopapular rash $(25 \%)$ \& Fixed drug eruptions $(21 \%)$ in decreasing order of frequency. Majority of reactions $(96 \%)$ were Bizarre/Unpredictable in nature. As a group, antimicrobials $(46 \%)$ were most frequently associated with CADR followed by NSAIDs (31\%) and antiepileptics (11\%). Most of the reactions (93\%) were mild-moderate and probable $(77 \%)$ in nature. Approximately $60 \%$ of ACDRs reported in this study were preventable.

Conclusions: There was slight male preponderance except acneiform eruptions. Cotrimoxazole being the most common offending drug then after Ibuprofen, Phenytoin among the anti-inflammatory, analgesics, antiepileptics class. Causality assessment resulted in high score $77 \%$ of probable category.
\end{abstract}

Keywords: Antimicrobials, Causality, Cutaneous adverse drug reactions, Pharmacovigilance

\section{INTRODUCTION}

There are no really 'safe' biologically active drugs. There are only safe physicians (Harold A. Kaminetzsky).

According to WHO an Adverse drug reaction (ADR) is defined as a response to a drug which is noxious and unintended, which occurs at doses normally used in man for prophylaxis, diagnosis or therapy of disease or for modification of physiological function excluding failure to accomplish the intended purpose (WHO). ${ }^{1}$

ADRs are now more numerous because:

- The number of drugs prescribed are high

- The ever-increasing number of new drugs in the market 
- $\quad$ Lack of formal system for monitoring adverse drug reactions. $^{2}$

ADRs are a cause of significant morbidity and mortality in patients of all areas of healthcare today. They are responsible for significant number of hospital admissions, among these; cutaneous ADRs (2-3\%) are one of the frequent reasons for patients to visit the physicians. ${ }^{3}$ It has been estimated that one third to as high as one half of ADRs are preventable. ${ }^{4}$ The incidence and severity of ADRs can be influenced by patient-related factors like age, sex, concurrent diseases, genetic factors, and drug related factors like type of drug, route of administration, duration of therapy, and dosage. The other important risk factors associated with adverse drug reactions are gender, increased number of drug exposures, advanced age, length of hospital stay and function of excreting organs (Beard, Edwards). 5,6

An adverse cutaneous drug reaction (ACDR) is any undesirable change in the structure or function of the skin, its appendages or mucous membranes and it encompasses all adverse events related to drug eruption, regardless of the etiology (Nayak and Acharjya). ${ }^{7}$ Any skin disorder can be imitated, induced, or aggravated by drugs. Many of the commonly used drugs have reaction rates over $1 \%$ (Roujeau and Stern). ${ }^{8,9}$ There is a wide spectrum of cutaneous adverse drug reactions varying from transient maculopapular rash to fatal toxic epidermal necrolysis (TEN) (Sharma and Sethuraman). ${ }^{10,11}$ The reported percentage of cutaneous reactions that physicians diagnose as potentially serious varies greatly and is estimated to be above 2 percent (Alanko et al, Ives et al). ${ }^{12,13}$

The incidence of cutaneous drug eruptions is about $2.2 \%$ and is higher amongst inpatients and females (Sehgal et al). ${ }^{14}$ However, according to Boston collaborative drug surveillance programme, 1973 the incidence of cutaneous drug reactions varies from 15-30\%. The incidence of ACDR in developed countries ranges from 1-3\% among in patients whereas in developing countries like India some studies peg it to $2-5 \%$ of the inpatients but there is lack of comprehensive data amongst out patients. ${ }^{15-21}$

Thus, the present study was undertaken to evaluate the clinical spectrum of all cutaneous ADRs in the outpatients attending the Deptartment of Dermatology. It also emphasises on the need and importance of an effective pharmacovigilance programme.

\section{METHODS}

The present study was a prospective one conducted by Dept. of Pharmacology in association with Dept. of Dermatology, Shri M.P. Shah medical college and G.G Hospital, Jamnagar. The study was conducted over a period of 6 months from August 08-January 09 after approval from Institutional Ethics Committee.
Prior to permission, Medical Superintendent of Shri G.G Hospital, Jamnagar, Dean of M.P. Shah medical college, Jamnagar and Head of Department of Dermatology, venereology and leprology were informed about the aims and objectives of the study and their co-operation was sought.

\section{Protocol development}

An appropriate study protocol and proforma for reporting adverse drug reactions was developed after discussion with the teaching staff members of Pharmacology and Skin department

\section{Inclusion criteria}

- All patients (of any age or either sex) who came to dermatology OPD with suspected adverse cutaneous drug reaction were included in the study.

- All patients referred from other depts. for suspected cutaneous ADR, who reported on OPD basis.

- All patients who reported in OPD and were subsequently admitted due to severity of ADR.

\section{Exclusion criteria}

- Cases where probable/possible offending drug could not be detected due to insufficient data were excluded from the study.

- Cases that were Unlikely, conditional or unassessible under WHO-UMC causality criteria were excluded from the study.

\section{RESULTS}

A total of 195 cases of suspected adverse cutaneous drug reactions were recorded during the period of study. Out of these 12 cases were excluded either because the offending drug was not identified or the data was insufficient to make any analysis. The remaining 183 cases were analyzed as under.

\section{Age and sex distribution of ACDR}

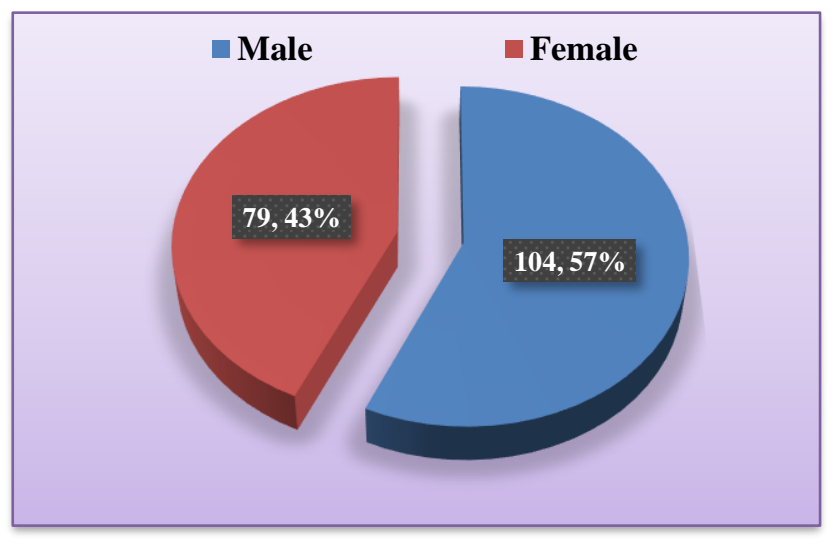

Figure 1: Sex distribution of ACDR. 
Out of 183 patients, $104(56.83 \%)$ were male and 79 $(43.17 \%)$ were female (Figure 1). Maximum patients (47.54\%) belonged to the age group of $25-44$ followed by 45-64 (28.42\%) and 15-24 (15.3\%) (Table 1).

In present study Mean age of patients with ACDR, Range and $\mathrm{M}: \mathrm{F}$ ratio were $36.47 \pm 27,4-70$ and $1.32: 1$ respectively.

\section{Individual type of cutaneous ADRs with age and sex}

In present study age and sex distribution of individual drug reactions are depicted in table 1 . The most common morphological varieties of drug reaction were
Urticaria/angioedema followed by Maculopapular rash $(25.14 \%)$ and Fixed drug eruptions $(21.31 \%)$. Together they accounted for $87 \%$ of all cases. Other types of cutaneous adverse drug reactions that were seen in our study included 7 cases of photosensitivity, 6 cases of acneiform eruptions, 3 cases of erythema multiforme and Erythroderma each, 2 cases of lichenoid drug eruption, 2 cases of toxic epidermal necrolysis (TEN) and 1 case of Stevens Johnson syndrome (SJS) (Figure 2). The results are comparable with other studies as shown in Table 2 .

Table 1: Age and sex distribution with individual type of cutaneous ADRs.

\begin{tabular}{|c|c|c|c|c|c|c|c|c|c|c|c|}
\hline $\begin{array}{l}\text { Age } \\
\text { (years) }\end{array}$ & Urticaria & $\begin{array}{l}\text { Maculo- } \\
\text { papular } \\
\text { Rash }\end{array}$ & FDE & Photosensitivity & $\begin{array}{l}\text { Acneiform } \\
\text { eruption }\end{array}$ & LDE & $\begin{array}{l}\text { Erythro- } \\
\text { derma }\end{array}$ & EM & SJS & TEN & $\%$ \\
\hline $0-4$ & & $1 \mathrm{M}$ & & & & & & & & & 0.55 \\
\hline $5-14$ & $2 \mathrm{M}, 3 \mathrm{~F}$ & $1 \mathrm{M}, 1 \mathrm{~F}$ & $2 \mathrm{M}$ & & & & & & & & 5.46 \\
\hline $15-24$ & $6 \mathrm{M}, 10 \mathrm{~F}$ & $2 \mathrm{M}, 3 \mathrm{~F}$ & $3 \mathrm{M}, 2 \mathrm{~F}$ & & $1 \mathrm{~F}$ & $1 \mathrm{~F}$ & $1 \mathrm{M}$ & & & & 15.30 \\
\hline $25-44$ & $22 \mathrm{M}, 11 \mathrm{~F}$ & $14 \mathrm{M}, 11 \mathrm{~F}$ & $11 \mathrm{M}, 9 \mathrm{~F}$ & $3 \mathrm{M}, 2 \mathrm{~F}$ & $1 \mathrm{M}, 2 \mathrm{~F}$ & $1 \mathrm{M}$ & & & & & 47.54 \\
\hline $45-64$ & $10 \mathrm{M}, 7 \mathrm{~F}$ & $8 \mathrm{M}, 4 \mathrm{~F}$ & $7 \mathrm{M}, 5 \mathrm{~F}$ & $1 \mathrm{M}, 1 \mathrm{~F}$ & $1 \mathrm{M}, 1 \mathrm{~F}$ & & $1 \mathrm{M}$ & $1 \mathrm{M}, 2 \mathrm{~F}$ & $1 \mathrm{M}$ & $1 \mathrm{M}, 1 \mathrm{~F}$ & 28.42 \\
\hline$\geq 65$ & $2 \mathrm{M}, 1 \mathrm{~F}$ & $1 \mathrm{M}$ & & & & & $1 \mathrm{~F}$ & & & & 2.73 \\
\hline Total & $42 \mathrm{M}, 32 \mathrm{~F}$ & $27 \mathrm{M}, 19 \mathrm{~F}$ & $23 \mathrm{M}, 16 \mathrm{~F}$ & $4 \mathrm{M}, 3 \mathrm{~F}$ & $2 \mathrm{M}, 4 \mathrm{~F}$ & $1 \mathrm{M}, 1 \mathrm{~F}$ & $2 \mathrm{M}, 1 \mathrm{~F}$ & $1 \mathrm{M}, 2 \mathrm{~F}$ & $1 \mathrm{M}$ & $1 \mathrm{M}, 1 \mathrm{~F}$ & 183 \\
\hline$\%$ & 40.44 & 25.14 & 21.31 & 3.83 & 3.28 & 1.09 & 1.64 & 1.64 & 0.55 & 1.09 & 100 \\
\hline
\end{tabular}

Table 2: Most commonly drug groups, individual drugs and Individual drug reactions.

\begin{tabular}{|c|c|c|c|}
\hline Drug Group & & $\begin{array}{l}\text { No. of } \\
\text { patients }\end{array}$ & $\%$ \\
\hline \multirow[t]{7}{*}{ Antimicrobials } & & 84 & 45.90 \\
\hline & Sulfonamides & 50 & 27.32 \\
\hline & Penicillins & 25 & 13.66 \\
\hline & Tetracyclines & 4 & 2.19 \\
\hline & Fluoroquinolones & 2 & 1.09 \\
\hline & Antimalarial & 2 & 1.09 \\
\hline & $\begin{array}{l}\text { Antitubercular } \\
\text { drugs }\end{array}$ & 1 & 0.55 \\
\hline \multirow[t]{4}{*}{ NSAIDS } & & 57 & 31.15 \\
\hline & Ibuprofen & 30 & 16.39 \\
\hline & Diclofenac & 22 & 12.02 \\
\hline & Indomethacin & 5 & 2.73 \\
\hline \multirow[t]{3}{*}{ Antiepileptics } & & 20 & 10.93 \\
\hline & Phenytoin & 16 & 8.74 \\
\hline & Carbamazepine & 4 & 2.19 \\
\hline PCM & & 13 & 7.10 \\
\hline \multirow[t]{8}{*}{ Others } & & 9 & 4.92 \\
\hline & $\beta$-Blockers & 2 & 1.09 \\
\hline & Steroids & 2 & 1.09 \\
\hline & ACE-i & 1 & 0.55 \\
\hline & CPZ & 1 & 0.55 \\
\hline & Ondansetron & 1 & 0.55 \\
\hline & $\mathrm{OCP}$ & 1 & 0.55 \\
\hline & Topical Retinoid & 1 & 0.55 \\
\hline
\end{tabular}

\section{Responsible drugs' group and individual drug reactions}

The most common causative drug groups were Antimicrobials (45.90\%), NSAIDS (31.15\%), Antiepileptic (10.93\%) (Table 2). Table 2, Figure 2 and 3 show a detailed list of various drugs that were implicated in one or the other adverse cutaneous drug reaction during our study period.

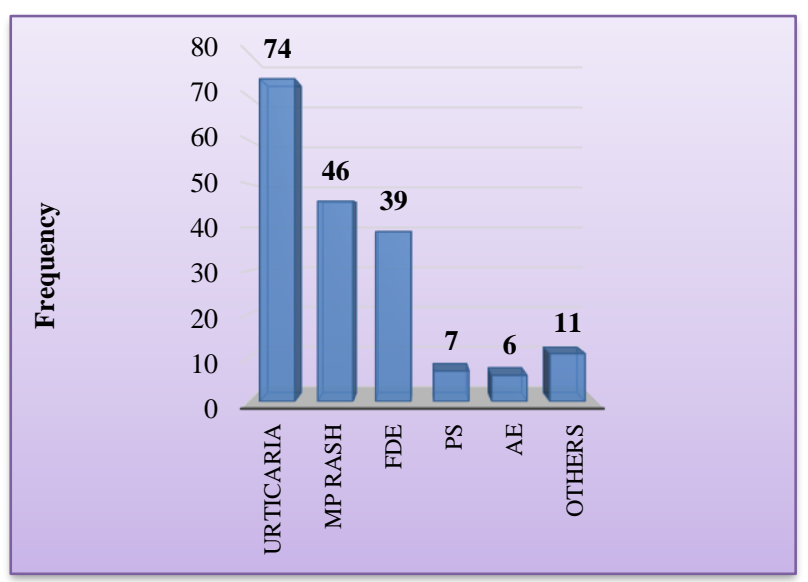

Figure 2: Type of ACDR.

Table 2, Figure 2 and 3 show NSAIDS and Antimicrobials drugs that were found to be responsible 
for Urticaria (40.54\%), Maculopapular rash (56.51\%), FDE $(61.55 \%)$ respectively. Sulfonamides and NSAIDs were responsible for $70 \%$ cases of FDE.

\section{Causality assessment using WHO-UMC criteria}

Cases that were unlikely, conditional or unassessible under WHO-UMC criteria were excluded from the study. Causality assessment of suspected ADRs shows out of 183 reported CADRs $27(14.75 \%)$ were assessed to be possible, $141(77.05 \%)$ as probable (Table 4$)$.

\section{Assessment of severity and preventability}

Reported reactions were found to be mild-moderate (171, $93.44 \%)$ followed by severe $(11,6.01 \%)$ and lethal $(1$,
$0.55 \%) .6 .56 \%$ reactions $(12 / 183)$ were considered serious as per WHO definition of serious adverse drug reaction (Table 5). Preventability of adverse cutaneous drug reaction was assessed by Schumock and Thornton criteria (Lau et al, Schumock and Thornton, Table 5).22,23

Table 3: Individual drug reactions

\begin{tabular}{|llll|}
\hline $\begin{array}{l}\text { Drug } \\
\text { reactions }\end{array}$ & $\begin{array}{l}\text { Urticaria } \\
(\mathbf{n}=74)\end{array}$ & $\begin{array}{l}\text { Maculopapular } \\
\text { rash } \\
(\mathbf{n}=46)\end{array}$ & $\begin{array}{l}\text { Fixed } \\
\text { drug } \\
\text { eruption } \\
(\mathbf{n}=39)\end{array}$ \\
\hline NSAIDS & $40.54 \%$ & $26.09 \%$ & $30.77 \%$ \\
\hline Antimicrobials & $37.83 \%$ & $56.51 \%$ & $61.55 \%$ \\
\hline Antiepileptics & $6.76 \%$ & $10.87 \%$ & $7.69 \%$ \\
\hline
\end{tabular}

Table 4: Causality assessment using WHO - UMC criteria.

\begin{tabular}{|lllll|} 
Causality type & $\begin{array}{l}\text { No. of } \\
\text { Cases }\end{array}$ & $\begin{array}{l}\text { Present study }(\mathbf{n = 1 8 3}) \\
\text { WHO-UMC criteria }\end{array}$ & $\begin{array}{l}\text { Noel et al. }(\mathbf{n = 5 6}) \\
\text { Naranjo's scale }\end{array}$ & $\begin{array}{l}\text { Ghosh et al. }(\mathbf{n = 5 3}) \\
\text { WHO-UMC criteria }\end{array}$ \\
\hline Definite & 15 & $8.20 \%$ & $2 \%$ & $5 \%$ \\
\hline Probable & 141 & $77.05 \%$ & $80 \%$ & $55 \%$ \\
\hline Possible & 27 & $14.75 \%$ & $18 \%$ & $40 \%$ \\
\hline Total & 183 & 100 & 100 & 100 \\
\hline
\end{tabular}

\section{DISCUSSION}

ADRs are a cause of significant morbidity and mortality in patients of all areas of healthcare today. It is important to monitor and report adverse drug reactions in order to promote safe and rational use of medicines.

Keeping these objectives in mind, a prospective hospital based observational study was carried out for duration of 6 months.

Table 5: Assessment of severity and preventability.

\begin{tabular}{|lll|}
\hline Severity of Reaction & No. of cases & $\%$ \\
\hline Mild - Moderate & 171 & 93.44 \\
\hline Severe & 11 & 6.01 \\
\hline Lethal & 1 & 0.55 \\
\hline Total & 183 & 100 \\
\hline Preventability of reaction & No. of Cases & $\%$ \\
\hline Preventable & 59 & 32.24 \\
\hline Probably Preventable & 5 & 2.73 \\
\hline Not preventable & 119 & 65.03 \\
\hline Total & 183 & 100 \\
\hline
\end{tabular}

During this period, a total of 195 cases of adverse cutaneous drug reaction were recorded. Out of these, 12 cases were excluded from the study because either the offending drug could not be identified or the data was insufficient to make reliable analysis.
The remaining 183 cases of ACDR were analyzed further.

\section{Age and sex distribution of ACDR}

Majority of patients in our study were males with M: F ratio being 1.32:1 (Table 1, Figure 1). The observations are similar to studies carried out elsewhere in India. ${ }^{11,24,25}$ However another study carried out by Pudukadan and Thapa at South Indian tertiary care centre reported male to female ratio as $0.87: 1 .^{21}$

The mean age of our patients with ACDR was 36.47 \pm 27 (95\% CI). The youngest patient was 4-year-old and the oldest was 70-year-old. This is in consonance with other Indian studies as shown in Table $2 .{ }^{11,24,26}$ However, two other studies noted that elderly are more commonly affected. ${ }^{27,28}$

The difference in various studies may be related to the regional variation in the healthcare seeking behavior of the population. ${ }^{11}$

\section{Type of cutaneous ADR}

Adverse cutaneous drug reactions vary in their patterns of morphology and distribution. In previous studies the most common morphologic patterns were exanthematous rash, urticaria and/or angioedema, fixed drug eruption and erythema multiforme (Stern and Wintroub). ${ }^{29}$ Of the various types of adverse cutaneous drug reactions seen in 
our study drug induced urticaria / angioedema was the most common (40.4\%) followed by Maculopapular rash $(25.14 \%)$ and Fixed drug eruptions $(21.31 \%)$. These observations are in conformity with study carried out by Chatterjee et al (Table 3). ${ }^{30}$

Others have noted exanthematous eruption (maculopapular rash) to be the most common type of drug reaction (Sullivan and Shear, Kauppinen and Stubb). ${ }^{31,32}$ A study from North India also found maculopapular rash to be most common type of ACDR. Pudukadan and Thapa and Patel and Marfatia found fixed drug eruptions as the most common drug eruption followed by maculopapular rash and urticaria. ${ }^{21,26}$

This variation could be due to different patterns of drug usage and different ethnic group characteristics in different parts of our country.

The age and sex distribution of other drug reactions is shown in Table 8. Acneiform eruptions were seen more commonly in females possibly because they are more conscious of this relatively asymptomatic eruption. Out of 9 cases of serious cutaneous adverse drug reactions, 6 were above 50 years of age suggesting that elderly are more likely to develop serious cutaneous adverse drug reactions. Factors which may predispose elderly to adverse drug reactions, include polypharmacy, increased potential for drug-drug interactions, age associated changes in pharmacokinetics and pharmacodynamics, altered homeostasis, multiple pathology and use of drugs with a narrow therapeutic margin (Nolan and O'malley). ${ }^{33}$

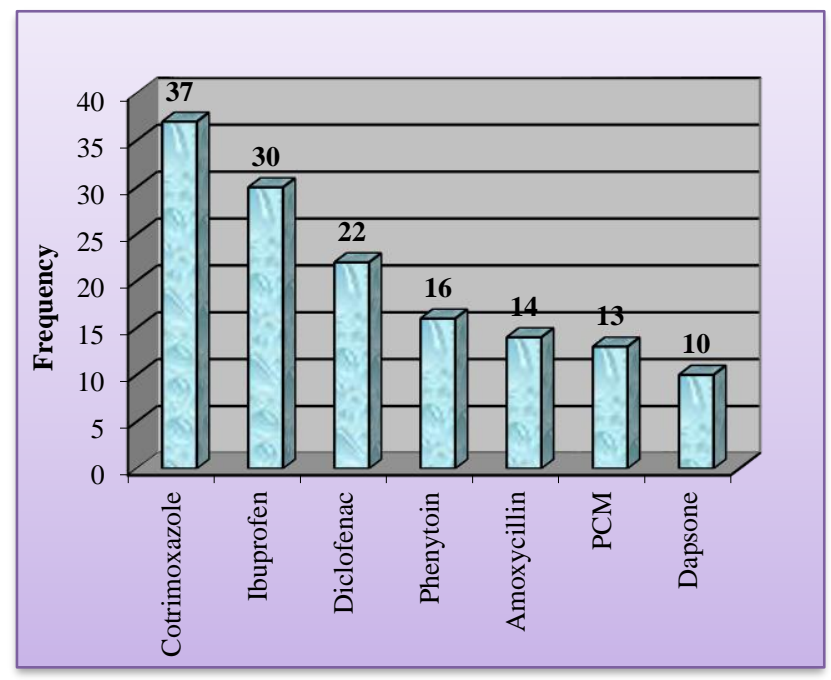

Figure 3: Most common drugs involved in ACDR.

\section{Type of adverse drug reaction}

Majority of adverse drug reactions 175 (95.63\%) were of Type B, since these reactions were totally aberrant effects that are not to be expected from the known pharmacological actions of a drug, when given in the usual therapeutic doses to a patient, whose body handles the drug in the normal way. The remaining 8 (4.37\%) ADRs belonged to Type A, since these reactions were the result of an exaggerated, but otherwise normal, pharmacological action, of a drug given in usual therapeutic doses.

Ghosh et al recorded $96 \%$ Type B reactions and only $4 \%$ Type A in their study which is quite similar to our result. $^{34}$

\section{Responsible drugs' groups and Individual drug reactions}

Most frequently reported adverse drug reactions were for Antimicrobial agents in 84 cases $(46 \%)$, followed by NSAIDs-57 cases $(31.15 \%)$ and antiepileptics-20 cases (11\%). Patel and Marfatia and Pudukadan and Thapa found similar results in their study. ${ }^{24,26}$ Also the results are in consonance with earlier reports (Mani and Mathew, Mehta et al, Kauppinen and Stubb). ${ }^{24,25,32}$ Sharma et al and Chatterjee et al reported antimicrobials as the major group followed by antiepileptics and NSAIDS (Table 2, Figure 2, 3 and 4).

Other studies have reported antiepileptics as the major group causing adverse cutaneous drug reactions followed by antimicrobials and NSAIDs. ${ }^{18}$

In the present study, among antimicrobials Sulfonamides (Cotrimoxazole and Dapsone) and Penicillins (Ampicillin/Amoxycillin) were the most commonly implicated drugs together accounting for almost $90 \%$ of all cases due to antimicrobials. Among NSAIDs majority of reactions were due to ibuprofen and diclofenac sodium. Phenytoin was responsible for $80 \%$ cases due to antiepileptics followed by carbamazepine. (Table 2, Figure 2, 3 and 4).

\section{Urticaria}

NSAIDs were the main culprit in causing urticaria and angioedema. They alone were responsible for $40.54 \%$ cases of urticaria. This was after excluding 10 cases (13.51\%) due to Paracetamol. Sulfonamides were the second most common cause of urticaria and they accounted for $24.32 \%$ cases. Penicillins were implicated in 7 cases $(9.46 \%$ ) (Table 2, Figure 2, 3 and 4).

The results are in accordance with earlier studies as shown in Table 1 and $2 .{ }^{10,26}$

\section{Maculopapular rash}

Penicillins were the most common cause of maculopapular rash in our study responsible for $30.43 \%$ cases followed by NSAIDs $(26.09 \%)$ and Sulfonamides (24\%) (Table 2, Figure 3). 
In contrast to other studies (Sharma et al, Noel et al, Chatterjee et al) where antiepileptics were the major drug groups responsible for more than $50 \%$ cases of maculopapular eruptions, phenytoin and carbamazepine accounted for only 5 cases $(11 \%)$ in our study. ${ }^{11,18,30}$ The results are however identical to a study carried out at Medical college, Vadodara (Patel and Marfatia) where antiepileptics were responsible for about $8 \%$ cases of maculopapular rash (Table 2).

\section{Fixed drug eruption}

Out of 39 cases of FDE, $16(41.03 \%)$ were due to sulfonamides alone mainly Cotrimoxazole. NSAIDs were involved in 12 cases (30.77\%) followed by 4 cases (10.26\%) due to Penicillins (Table 1, 2, Figure 3).

These results are in consonance with earlier studies conducted in other parts of India (Table 2). ${ }^{11,26}$

\section{Other drug reactions}

Apart from these, 7 cases of Photosensitivity were recorded which account for $3.82 \%$ of total reactions. The results are similar to earlier studies conducted in India. ${ }^{21,26} 2$ cases each were due to ibuprofen and doxycycline; 1 each due to chlorpromazine, topical retinoid and topical silver sulfadiazine.

6 cases $(3.27 \%)$ of Acneiform eruptions were recorded. 3 were due to phenytoin, 2 due to steroids and 1 due to oral contraceptive pills. The results comply with earlier studies. $^{21,26}$

There were 2 cases of Lichenoid drug eruption, 1 each due to chloroquine and carbamazepine. 3 cases of Erythroderma due to chloroquine, dapsone and phenytoin were observed accounting for $1.64 \%$ of all reactions.

During the study 3 cases of erythema multiforme (sulphonamides-2, NSAID-1), one case of SJS due to cotrimoxazole and 2 cases of TEN due to phenytoin and carbamazepine were reported. The results are similar to the study carried out at N.R.S Medical college and hospital, Kolkata. ${ }^{18}$ However, Pudukadan and Thapa reported $6.7 \%$ cases of erythema multiforme as opposed to only $1.64 \%$ seen in our study. ${ }^{21}$

\section{Causality assessment}

There is no gold standard investigation for confirmation of a drug-induced reaction. Instead diagnosis and assessment of a drug cause involve analysis of a constellation of features such as timing of drug exposure and reaction time, course of reaction with dilig withdrawal/discontinuation, timing and nature of a recurrent eruption on rechallenge, a history of similar reaction to the suspected drug and previous reports of similar reactions to the same drug. ${ }^{35}$
In this study, WHO causality definitions were used to categorize the ADRs into definite, probable and possible categories as it is a very simple and widely accepted method to assess causality.

In our study 183 cases of ACDR were seen. Dechallenge was done in all the cases and it was positive in 156 of them. Out of these $15(8 \%)$ were definite. Although rechallenge was not done in any of our cases due to practical problems, these cases were considered definite because rechallenge data was available in the form of past history of similar reaction with the same drug. The remaining 141 cases $(77 \%)$ were probable. 27 cases (15\%) were considered possible because dechallenge data was either negative or doubtful and the reaction could be attributed to existing clinical condition (Table 4).

In a study carried out at Manipal College of Pharmaceutical Sciences, Ghosh et al reported 5\% definite, $55 \%$ probable and $40 \%$ possible ACDR. However, the study included inpatients as well and it utilised Naranjo's scale for causality assessment. Noel et al have reported $2 \%$ definite, $80 \%$ probable and $18 \%$ possible reactions utilising WHO causality criteria (Table 4).

The differences in various studies may be due to different scales used for causality assessment or because of individual differences in the interpretation of data.

\section{Assessment of severity and preventability}

171 patients $(93.44 \%)$ had mild - moderate adverse cutaneous drug reaction as they didn't require any specific therapy. They were simply managed by withdrawal of the suspected drug and supportive treatment. 12 patients $(6.56 \%)$ suffered severe adverse drug reaction and required immediate cessation of the suspected drug, hospitalization and intensive medical care (Table 5). The results comply with earlier studies (Pudukadan and Thapa, Ghosh et al). ${ }^{21,34}$

Schumock and Thornton criteria was used for assessment of preventability. $^{22} 59$ reactions $(32.24 \%)$ were considered definitely preventable as 26 patients had history of similar reaction in the past; 14 had allergy; in 19 cases the drug was not appropriate for the patients clinical condition e.g. antibiotics given for viral infection like common cold. ${ }^{22} 5$ reactions $(3 \%)$ were considered probably preventable as they involved poor patient compliance, potential drug interaction and failure to do therapeutic drug monitoring. The remaining 119 reactions $(65 \%)$ were regarded as Not preventable (Table 5).

\section{Assessment of seriousness}

Adverse drug reactions were considered serious on the basis of WHO definition of serious adverse reaction (National pharmacovigilance protocol). During our study, 12 serious cutaneous reactions were reported. 2 patients 
were of toxic epidermal necrolysis (TEN), one of which died due to septicemia and multiple organ failure after being admitted to hospital while another recovered with blurring of vision as there was severe ocular involvement.

\section{CONCLUSION}

To sum up, the occurrence of cutaneous adverse drug reactions in the present study was similar in many ways to other studies conducted in India. A wide clinical spectrum of cutaneous ADRs ranging from mild Urticaria and Maculopapular rash to serious SJS and TEN was observed.

Points of interest that could be concluded from this study are:

- Majority of the patients (48\%) with ACDR belonged to the age group 25-44 followed by 45-64 (28\%). There was slight male preponderance with $\mathrm{M}: \mathrm{F}$ ratio being 1.32:1. Acneiform eruptions in contrast showed female predominance $(\mathrm{M}: \mathrm{F}=1: 2)$. Most frequent adverse cutaneous drug reactions reported were Urticaria (40\%), Maculopapular rash (25\%) and Fixed drug eruptions $(21 \%)$ in decreasing order of frequency. Majority of reactions (96\%) were Bizarre/Unpredictable in nature and occurred due to hypersensitivity reaction. Only $4 \%$ were Augmented/Predictable.

- As a group, antimicrobials (46\%) were most frequently associated with ACDR followed by NSAIDs $(31 \%)$ and antiepileptics (11\%). Individually speaking, commonly incriminated drugs in this study in decreasing order of frequency were cotrimoxazole (37), ibuprofen (30), diclofenac sodium (22), phenytoin (16), amoxycillin (14), paracetamol (13) and dapsone (10).

- Using WHO-UMC causality definitions, 77\% of ACDRs were probable, $15 \%$ possible and only $8 \%$ were definite in nature. Most of the reactions (93\%) were mild-moderate in nature and could be managed by supportive treatment and withdrawal of the culprit agent. Only 7\% reactions were of severe grade that required intensive medical care.

\section{ACKNOWLEDGMENTS}

Authors are thankful to all staff members of paediatric department, Guru Gobind Government Hospital, Jamnagar, especially Dr. Bhadresh Vyas (M.D. Professor and Head, Department of Pediatrics), Dr. Sonal Shah (M.D. Additional Professor, Department of Pediatrics), Jamnagar and Dr. S. D. Mistry (Head of Department, Pharmacology) for their kind cooperation, guidance and support for successful completion of the study. Authors are also grateful to our pediatric patients and their parents/guardians for their cooperation in this study.
Funding: No funding sources

Conflict of interest: None declared

Ethical approval: The study was approved by the Institutional Ethics Committee

\section{REFERENCES}

1. WHO 1972, International drug monitoring. Role of national centres. WHO Technical report series no. 498. Geneva, Switzerland.

2. Bates DW, Spell N, Cullen DJ. The cost of adverse drug reactions in hospitalized patients. JAMA. 1997;227:307-11.

3. Bigby M, Jick SJ, Kien H, Amdt K. Drug-induced cutaneous reactions a report from the Boston Collaborative Drug Surveillance Program on 15. 438 consecutive in patients 1975 to 1982. JAMA; 1986:3358-3363.

4. Barbara SM. In: Shargel L Eds. Comprehensive Pharmacy Review, 4th Ed, Lippincott Williams and Wilkins, London; 2001:416.

5. Beard K. In: Lee A Eds. Adverse drug reactions, 1st Ed, Pharmaceutical Press, London; 2001:1.

6. Edwards IR. In: Speight TM, Nicholas HG Eds. Avery's Drug Treatment, 4th Ed, Adis International; 1997:261.

7. Surajit N, Acharjya B. Adverse cutaneous drug reaction. Indian J Dermatol. 2008:53(1):2-8.

8. Roujeau X, Huynh TN, Bracq C, Guilluame JC, Revuz J, Touraine R. Genetic susceptibility to toxic epidermal necrolysis. Arch Dermatol. 1987;123:1171-3.

9. Stern RS, Wintroub BU. Cutaneous reactions to drugs. In: Freedberg IM, Eisen AZ, Wolff K, Austen KF, Goldsmith LA, Katz SI et al editors. Fitzpatrick's Dermatology in general medicine. 5th ed. New York: McGraw-Hill; 1999:1634-42.

10. Sharma VK, Sethuraman G. Adverse cutaneous reactions to drugs: an overview. J Postgrad Med. 1996;42:15-22.

11. Sharma VK, Sethuraman G, Kumar B. Cutaneous adverse drug reactions: clinical pattern and causative agents-a six-year series from Chandigarh. India. J Postgrad Med. 2001;47:95-9.

12. Alanko K, Stubb S, Kauppinen K. Cutaneous drug reactions, Clinical types and causative agents in a five-year survey of in patients (1981-1985). Acta Derm Venereol (Stockh). 1989;69:223-6.

13. Ives TJ, Bentz EJ, Gwyther RE. Dermatologic adverse drug reactions in a family medicine setting. Arch Fam Med. 1992;1:241-5.

14. Sehgal S, Balachandran C, Shenoi SD. Clinical study of cutaneous drug reaction in 80 patients. Indian $\mathbf{J}$ Dermatol Venereol Leprol. 2003;69:6-7.

15. Boston University Medical Centre. Dipyrone as a cause of drug rashes: an epidemiologic study: a report from the Boston collaborative drug surveillance program. Int J Epidemiol. 1973;2:16770 . 
16. Bigby M. Rates of cutaneous reactions to drugs. Arch Dermatol. 2001;137:765.

17. Craig KS, Edward WC, Anthony AG. Cutaneous drug reactions. Pharmacol Reviews. 2001;53:357-79.

18. Noel MV, Sushma M, Guido S. Cutaneous adverse drug reactions in hospitalized patients in a tertiary care centre. Indian J Pharmacol. 2004;36:292-5.

19. Uppal R, Jhaj R, Malhotra S. Adverse drug reactions among inpatients in a north Indian referral hospital. Natl Med J India. 2000;13:16-8.

20. Ramesh M, Pandit J, Parthasarathi G. Adverse drug reactions in a South Indian hospital-their severity and cost involved. Pharmacoepidemiol Drug Safety 2003; 12:687-92.

21. Pudukadan D, Thappa DM. Adverse cutaneous drug reactions: Clinical pattern and causative agents in a tertiary care center in South India. Indian J Dermatol Venereal Leprol. 2004;70:20-4.

22. Lau PM, Stewart K, Dooley M. The ten most common adverse drug reactions in oncology patients: do they matter to you? Support care cancer. 2004;12:626-33.

23. Schumock G, Thornton J. Focusing on the preventability of adverse drug reactions. Hosp Pharm. 1992;27:538

24. Mani MZ, Mathew M. A study of 218 drug eruptions. Indian J Dermatol Venereol Leprol. 1983;49:109-17.

25. Mehta TK, Marquis L, Shelty JN. A study of 70 cases of drug eruptions. Indian $\mathbf{J}$ Dermatol Venereol Leprol. 1971;37:1-5.

26. Patel RM, Marfatia YS. Clinical study of cutaneous drug eruptions in 200 patients. Indian J Dermatol Venereol Leprol. 2008;74:80.

27. Leape LL, Brennan TA, Laird N, Lawthers AG, Localio AR, Brarnes BA et al. The nature of adverse drug events in hospitalized patients - Result of the Harvard medical practice study-II. N Eng J Med. 1991;324:377-84.
28. Hafner JW, Belknap SW, Squillante MD, Bucheit KA. Adverse drug events in emergency department patients. Ann Emerg Med. 2002;39:258-67.

29. Stern RS, Wintroub BU. Cutaneous reactions to drugs. In: Freedberg IM, Eisen AZ, Wolff K, Austen KF, Goldsmith LA, Katz SI, et al, editors. Fitzpatrick's Dermatology in general medicine. 5th ed. New York: McGraw-Hill; 1999:1634-42.

30. Chatterjee S, Ghosh AP, Barbhuiya J, Dey SK. Adverse cutaneous drug reactions: A one year survey at a dermatology outpatient clinic of a tertiary care hospital. Indian J Pharmacol. 2006;38(6):429-31.

31. Sullivan JR, Shear NH. Drug eruptions and other adverse drug effects in aged skin. Clin Geriatr Med. 2002;18:21-42.

32. Kauppinen K, Stubb S. Drug eruptions: Causative agents and clinical types. Acta Derm Venereol. 1984;64:320-4.

33. Nolan L, O'Malley K. Adverse drug reaction in the elderly. Br J Hosp Med. 1989;41:446-57.

34. Ghosh S, Acharya LD, Rao PGM. Study and evaluation of the various cutaneous adverse drug reactions in Kasturba hospital, Manipal. Indian $\mathbf{J}$ Pharm Sci. 2006;68(2):212-5.

35. Shear NH, Knowles SR, Sullivan JR, Shapiro L. Cutaneous reactions to drugs. In: Freedberg IM, Eisen AZ, Wolff K, editors. Fitzpatrick's dermatology in general medicine. 6th Ed. USA: McGraw Hill, Medical publishing division; 2003:1330-6.

Cite this article as: Chavda DA, Suthar SD, Singh S, Balat JD, Parmar SP, Mistry SD. A study of cutaneous adverse drug reactions in the outpatient department of Dermatology at a tertiary care center in Gujarat, India. Int J Basic Clin Pharmacol 2017;6:1115-22. 